\title{
Mandatory oral glucose tolerance tests identify more diabetics in stable patients with chronic heart failure: a prospective observational study
}

An LM Stevens ${ }^{1 *}$, Dominique Hansen ${ }^{1,2}$, Vincent Vandoren ${ }^{1}$, Rob Westerlaken ${ }^{1}$, An Creemers $^{3}$, Bert O Eijnde ${ }^{1 \dagger}$ and Paul Dendale ${ }^{1,2+}$

\begin{abstract}
Background: Many patients with chronic heart failure (CHF) are believed to have unrecognized diabetes, which is associated with a worse prognosis. This study aimed to describe glucose tolerance in a general stable CHF population and to identify determinants of glucose tolerance focusing on body composition and skeletal muscle strength.

Methods: A prospective observational study was set up. Inclusion criteria were diagnosis of CHF, stable condition and absence of glucose-lowering medication. Patients underwent a $2 \mathrm{~h}$ oral glucose tolerance test (OGTT), isometric strength testing of the upper leg and dual energy $x$-ray absorptiometry. Health-related quality of life and physical activity level were assessed by questionnaire.

Results: Data of 56 participants were analyzed. Despite near-normal fasting glucose values, 55\% was classified as prediabetic, $14 \%$ as diabetic, and $20 \%$ as normal glucose tolerant. Of all newly diagnosed diabetic patients, $79 \%$ were diagnosed because of $2 \mathrm{~h}$ glucose values only and none because of HbA1c. Univariate mixed model analysis revealed ischaemic aetiology, daily physical activity, E/E', fat trunk/fat limbs and extension strength as possible explanatory variables for the glucose curve during the glucose tolerance test. When combined in one model, only fat trunk/fat limbs and E/E' remained significant predictors. Furthermore, fasting insulin was correlated with fat mass/height ${ }^{2}(r=0.51, p<0.0001)$, extension strength $(r=-0.33, p<0.01)$ and triglycerides $(r=0.39, p<0.01)$.

Conclusions: Our data confirm that a large majority of CHF patients have impaired glucose tolerance. This glucose intolerance is related to fat distribution and left ventricular end-diastolic pressure.
\end{abstract}

Keywords: Insulin resistance, Body composition, Muscle strength, Quality of life

\section{Background}

Chronic heart failure (CHF) is a system disease. Apart from cardiac failure, the clinical picture involves pulmonary, renal, hepatic and skeletal muscle abnormalities [1]. In addition, diabetes mellitus type 2 is frequently found, with percentages varying from $8-41 \%$ [2]. Although the suspicion arises that impaired glucose tolerance is the rule rather than the exception in this population, its exact prevalence is not known [2,3].

\footnotetext{
*Correspondence: an.stevens@uhasselt.be

${ }^{\dagger}$ Equal contributors

${ }^{1}$ REVAL Rehabilitation Research Centre, Hasselt University, Martelarenlaan 42 BE-3500 Hasselt, Belgium

Full list of author information is available at the end of the article
}

In CHF patients with reduced systolic function, left ventricular ejection fraction and aetiology of CHF have been described as predictive factors for insulin sensitivity [4-9]. Furthermore, typical CHF medical therapies, i.e. ACE inhibitors, $\beta$-blockers and thiazides are believed to influence glucose tolerance [10-14].

Although a higher body mass index is associated with impaired glucose tolerance and diabetes, it is also associated with better survival in CHF [15]. When dividing body weight into fat mass and lean mass, it could be hypothesized that a higher fat mass leads to overall detrimental effects, while a higher lean mass is associated with reduced catabolism and beneficial effects in CHF [16]. In addition, a higher muscle mass could lead to 
elevated glucose uptake. Precise measurement of body composition would therefore provide new insights in the relation between body composition and glucose tolerance in CHF.

As skeletal muscle strength is also an independent predictor for survival in CHF, it could be hypothesized that not only the quantity but also the quality of skeletal muscle plays an important role [17]. Still, skeletal muscle function has not been investigated in relation to glucose tolerance in CHF yet.

Following this line of reasoning, the present study aims to describe glucose tolerance in relation to (a) severity of heart failure, (b) the intake and dosage of typical CHF medical therapies and (c) body composition and skeletal muscle strength in a heterogeneous group of stable CHF patients.

\section{Methods}

\section{Subjects}

Patients diagnosed with CHF were recruited from the heart failure clinic of the Jessa hospital (Hasselt, Belgium). Inclusion criteria were (1) a history of CHF of at least 6 months and (2) clinically stable for more than 3 months prior to the onset of the study. Known diabetes with glucose lowering therapy, engagement in phase III rehabilitation in a hospital setting and other chronic diseases (pulmonary disease, end-stage renal disease, cancer) were the exclusion criteria. Based on a previous study, sample size was estimated on 60 patients [7]. All patients gave their written informed consent. Ethical approval of the study was obtained from the committees of the Jessa hospital and Hasselt University. The investigation conforms with the principles outlined in the Declaration of Helsinki.

\section{Study design}

In this prospective observational study, patients underwent a $2 \mathrm{~h}$ oral glucose tolerance test (OGTT), had a late breakfast and muscle strength and body composition were assessed on a single test day. During the OGTT, health-related quality of life and physical activity level questionnaires were completed and current medical therapy was registered.

\section{Oral glucose tolerance test and blood parameters}

Following an overnight fasting period, baseline blood glucose and insulin concentrations as well as blood lipids, HbA1c and B-type Natriuretic Peptide (BNP) were determined via a venous blood sample. Hereafter, $75 \mathrm{~g}$ glucose (Merck KGaA, Darmstadt, Germany) dissolved in $250 \mathrm{~mL}$ water was ingested and 1- and 2 hours blood samples were taken for glucose and insulin analysis. Blood samples for glucose and insulin (in serum separation tubes) and BNP (in EDTA tubes) were maintained at room temperature for $30 \mathrm{~min}$, centrifuged, and the collected serum and plasma were frozen at $-80^{\circ} \mathrm{C}$ until analysis. Blood samples for lipids (in lithium heparin tubes) and HbA1c (in EDTA tubes) were processed on the test day. Glucose, total cholesterol and HDL cholesterol were determined with an Olympus AU analyzer (Beckman Coulter, Switzerland), insulin and BNP with ADVIA Centaur (Siemens Medical Solutions Diagnostics, Germany) and HbA1c with Hi- Auto A1C Analyzer (Menarini Diagnostics, Italy). Serum glucose was converted to plasma glucose using the following formula: plasma glucose $(\mathrm{mmol} / \mathrm{L})=-0.137+$ $\left(1.047^{*}\right.$ serum glucose $\left.(\mathrm{mmol} / \mathrm{L})\right)$ [18]. Subjects were divided into 3 groups according to their glucometabolic state as recommended by the American Diabetes Association (see Table 1) [19]. Reference values for insulin during OGTT were 3-28 mU/L at fasting state, 29$88 \mathrm{mU} / \mathrm{L} 1 \mathrm{~h}$ after glucose load and 22-79 mU/L $2 \mathrm{~h}$ after glucose load [20].

\section{Muscle strength}

Maximal voluntary unilateral strength of the upper leg was evaluated in a seated position on an isokinetic dynamometer (System 3; Biodex Medical Systems, New York, USA). The rotational axis of the dynamometer was aligned with the transverse knee joint axis and connected to the distal end of tibia. Subjects performed 2 maximal isometric knee extensions and flexions at knee angles of $45^{\circ}$ and $90^{\circ}$. Maximal contractions (4 s) were interspersed by $30 \mathrm{~s}$ rest intervals. The highest isometric extension and flexion torques $(\mathrm{Nm})$ at each knee angle were selected as peak torque. Maximal strength was expressed as peak torque relative to lean tissue of the right leg.

\section{Body composition}

To determine body composition, a Dual Energy X-ray Absorptiometry scan (Hologic, Vilvoorde, Belgium) was performed. Fat tissue mass and lean tissue mass were obtained for the whole body and for the following separate regions: legs, trunk, gynoid and android region. From these findings, the following indices were calculated: waist-to-hip fat mass ratio (android fat (g)/gynoid fat (g) ratio), fat of the trunk/fat mass of the limbs ratio.

Table 1 Criteria used for glucometabolic classification

\begin{tabular}{lccc}
\hline & NGT & Prediabetes & Diabetes \\
\hline Fasting glucose & $<5.6 \mathrm{mmol} / \mathrm{L}$ & $5.6-6.9 \mathrm{mmol} / \mathrm{L}$ & $\geq 7.0 \mathrm{mmol} / \mathrm{L}$ \\
OR & & & \\
2-hour glucose & $<7.8 \mathrm{mmol} / \mathrm{L}$ & $7.8-11.0 \mathrm{mmol} / \mathrm{L}$ & $\geq 11.1 \mathrm{mmol} / \mathrm{L}$ \\
OR & & & \\
HbA1c & $<5.7 \%$ & $5.7-6.4 \%$ & $\geq 6.5 \%$ \\
\hline
\end{tabular}

NGT, normal glucose tolerance. 


\section{Medical history and echocardiography}

Hospital records were retrospectively reviewed for aetiology of heart failure (ischaemic versus non-ischaemic), and for left ventricular ejection fraction (EF) in the most recent echocardiography. In 25 patients, echocardiography was performed in the month following OGTT, with determination of $\mathrm{E} / \mathrm{E}$ '.

\section{Health related quality of life and physical activity}

The EQ-5D was used to evaluate health related quality of life. It is a standardized, non-disease-specific instrument for describing and valuing health, which is limited in length (5 short questions and a visual analogue scale) $[21,22]$. Daily physical activity was assessed using the International Physical Activity Questionnaire.

\section{Statistical analysis}

Statistical analyses were performed using SAS Enterprise Guide 4.3, SAS 9.2 (SAS Institute Inc., Cary, NC) and R2.10.1 software. All measures are presented as mean \pm SD. Continuous data were compared using nonparametric one way ANOVA and post hoc multiple comparison procedures were performed using Wilcoxon rank sum test with Bonferroni correction. Categorical data were compared using Fisher exact test. Because the glucose curve consists of longitudinal data (3 time points for each patient), relations between the glucose curve and other patient characteristics (explanatory variables) were investigated with mixed model analysis. Multiple imputation (number of imputed datasets $=5$ ) was performed for E/E' based on the glucose levels during OGTT [23]. Bivariate correlation (Spearman) was performed between fasting insulin and predictive variables. All tests were two-sided with a P-value of 0.05 as threshold for statistical significance.

\section{Results}

From March 2011 to March 2012, a total of 480 patients were screened. A patient flow diagram is presented in Figure 1.

\section{Oral glucose tolerance test}

Despite near-normal mean fasting glucose in the total group $(5.7 \pm 0.6 \mathrm{mmol} / \mathrm{L}), 14$ patients $(25 \%)$ were classified as having newly diagnosed diabetes, 31 (55\%) as having prediabetes and $11(20 \%)$ as having NGT. Overt diabetes was diagnosed because of $2 \mathrm{~h}$ glucose values only in $79 \%$ of patients, while only 3 patients could be diagnosed because of fasting glucose values and none because of HbA1c (Table 2). Glucose and insulin curves during OGTT are presented in Figure 2. In all 3 groups, mean fasting insulin levels were in the normal range but increased above reference values $1 \mathrm{~h}$ after glucose load.

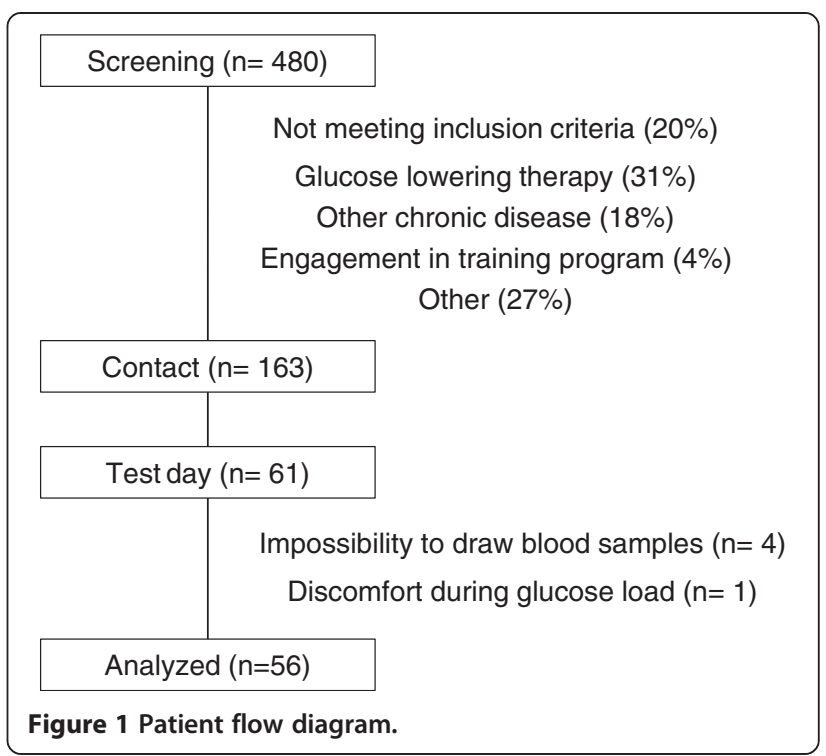

Two hours after glucose load, insulin curves did not decline in prediabetics and diabetics.

\section{Patient characteristics and body composition}

Table 3 shows patient characteristics of the 3 groups. Differences in New York Heart Association class distribution and BNP values between groups were not significant. Medical treatment, EF, age, gender, whole body weight and fat mass were comparable between groups. Fat distribution expressed as fat trunk/fat limb ratio tended to be higher in diabetics compared to prediabetics and NGT $(p<0.03)$. However, these differences did not reach significance after Bonferroni correction.

\section{Muscle strength}

Maximal isometric strength was comparable between groups.

\section{Health related quality of life and physical activity}

The total score of the EQ5D was similar in all 3 groups (data not shown), as well as overall self-rated health status

Table 2 Importance of 2-hour glucose values for glucometabolic classification

\begin{tabular}{lcc}
\hline & $\begin{array}{c}\text { Prediabetes } \\
\mathbf{n = 3 1}\end{array}$ & $\begin{array}{c}\text { Diabetes } \\
\mathbf{n = 1 4}\end{array}$ \\
\hline Fasting glucose & $5(16 \%)$ & $1(7 \%)$ \\
Fasting + 2 h glucose & $4(13 \%)$ & $2(14 \%)$ \\
Fasting glucose + Hba1c & $6(19 \%)$ & - \\
Fasting glucose + 2 h glucose + HbA1c & $3(10 \%)$ & - \\
2-hour glucose & $4(13 \%)$ & $11(79 \%)$ \\
2 h glucose + HbA1c & $6(19 \%)$ & - \\
HbA1c & $3(10 \%)$ & - \\
\hline
\end{tabular}

Data are presented as frequency and percentage. 


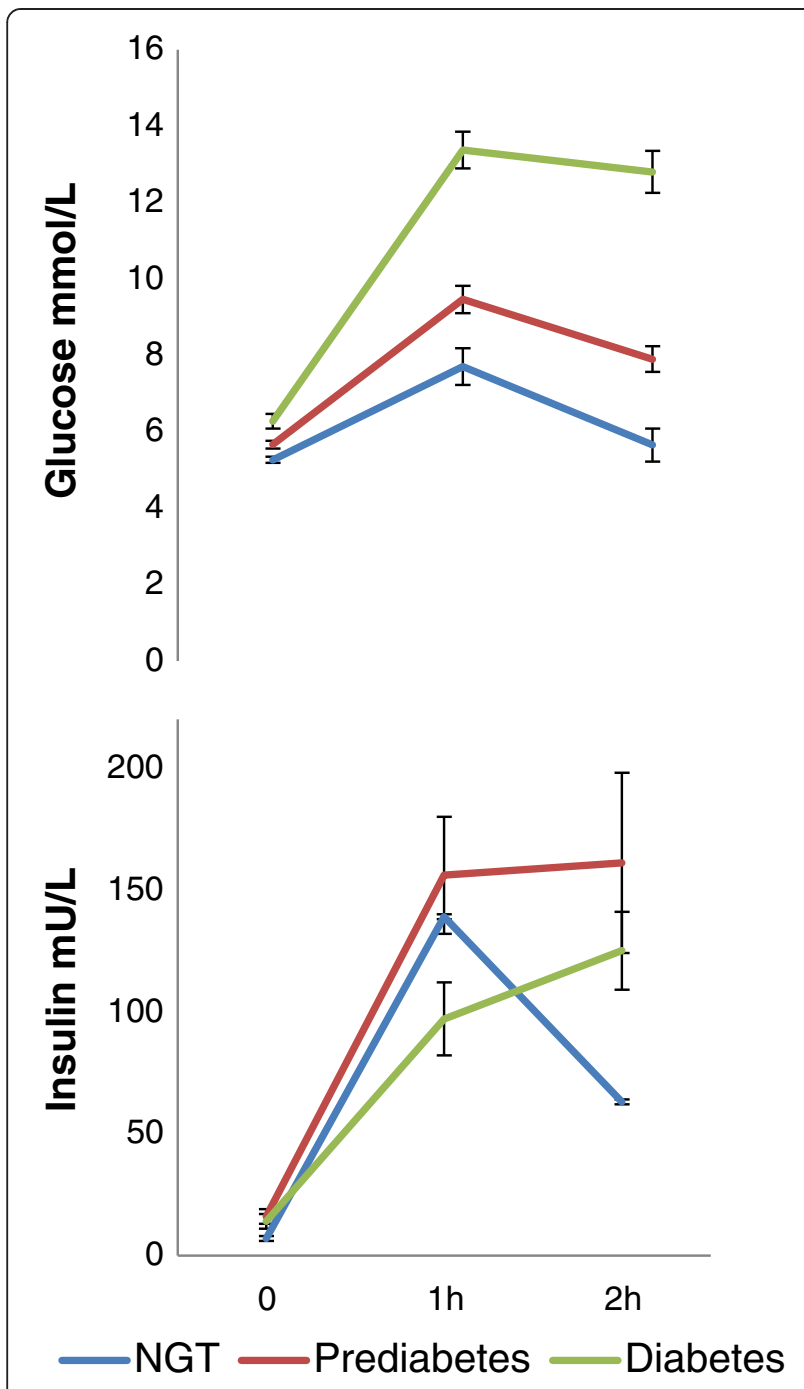

Figure 2 Glucose and insulin concentrations during 2 h OGTT. Data are shown as mean \pm SE. NGT: normal glucose tolerance.

(NGT: $7.0 \pm 1.0$, prediabetics: $6.7 \pm 1.9$, diabetics: $6.4 \pm 2.0$; $\mathrm{p}=0.90$ ). Also reported daily physical activity did not differ between groups.

\section{Contributors to glucose tolerance}

Univariate mixed model analysis revealed 6 possible explanatory variables for the glucose values during OGTT: ischaemic aetiology, daily physical activity, E/E', android/ gynoid fat ratio, fat trunk/fat limbs and knee extension strength at $90^{\circ}$. Android/gynoid fat ratio was excluded from the final model building because of interference with the other fat distribution variable. When the remaining 5 variables were combined in one model with random intercept, and after manual backward selection procedure, fat distribution showed a main effect for overall glucose values. Furthermore, E/E' and fat distribution also showed an interaction effect with glucose curve over time. Multiple imputation analysis produced the same results.

Because insulin release after glucose loading was decreased in the diabetic group, and the insulin curves therefore did not follow the same increasing trend as the glucose values, mixed model analysis was not performed for the insulin curves. Instead, fasting insulin was found to correlate moderately with body mass index $(\mathrm{r}=0.51$, $\mathrm{p}<0.0001)$ and fat mass $/$ height $^{2}(\mathrm{r}=0.51, \mathrm{p}<0.0001)$. Fasting insulin was also slightly related with total body fat $(\% ; \mathrm{r}=0.49, \mathrm{p}=0.0001)$, triglycerides $(\mathrm{r}=0.39, \mathrm{p}<0.01)$ and quadriceps strength at $45^{\circ}(\mathrm{r}=-0.33, \mathrm{p}=0.01)$.

\section{Discussion}

Despite near-normal fasting glucose values, our data show that the majority of stable CHF patients have impaired glucose tolerance. This was related to body composition and left ventricular end-diastolic pressure, but not to severity of heart failure symptoms, severity of left ventricular dysfunction, nor typical medical therapies.

\section{Description of glucose tolerance}

In our study population, $80 \%$ showed an abnormal reaction to glucose intake. This was easily detected using a $2 \mathrm{~h}$ oral glucose tolerance test, as proposed by the American Diabetes Association [19]. In fact, only $21 \%$ of patients with diabetes would be correctly classified using fasting glucose values only, and none using HbA1c.

Glucose values were in the prediabetic range in $55 \%$ of the patients, and in the diabetic range in $25 \%$. The proportion of prediabetes and undetected diabetes is much higher in this study when compared to the findings of other studies, reporting $22-23 \%$ prediabetes and $18 \%$ newly diagnosed diabetes in a selected population of CHF patients with reduced EF $[3,9]$. This may be due to the heterogeneous study population irrespective of EF. Furthermore, it is related to the use of stricter glucose cutoff values in addition to HbA1c values for diagnosis of (pre)diabetes in the present study.

The prognostic impact of this finding is enormous. A stepwise increasing mortality rate with increasing glucose intolerance assessed by OGTT was found by Egstrup et al. [24]. Consequently, 80\% of the study population, which represented the general CHF population without glucose lowering therapy in the heart failure clinic, is at higher risk for mortality compared to other CHF patients with normal glucose tolerance. Therefore, the transition into overt diabetes and worse prognosis should be prevented. Treatment of (pre)diabetic CHF patients with glucose lowering medication is not evident, as they may be contra-indicated in this population [25]. Therefore, diet counseling and exercise therapy are the preferred treatment methods. Although evidence points to a possible beneficial effect of exercise therapy on 
Table 3 Comparison of patients characteristics according to glucometabolic state

\begin{tabular}{|c|c|c|c|c|}
\hline & NGT $n=11$ & Prediabetes $n=31$ & Diabetes $n=14$ & $p$ \\
\hline Age (years) & $64 \pm 17$ & $69 \pm 11$ & $70 \pm 11$ & .58 \\
\hline Sex (\% male) & 91 & 58 & 64 & .15 \\
\hline $\mathrm{BMI}\left(\mathrm{kg} / \mathrm{m}^{2}\right)$ & $25.1 \pm 3.7$ & $27.6 \pm 5.5$ & $29.9 \pm 9.7$ & .39 \\
\hline Aetiology (\% IHD) & 27 & 32 & 57 & .22 \\
\hline NYHA class (\% I-II-III) & $55-36-9$ & $23-48-29$ & $21-57-21$ & .34 \\
\hline LVEF (\%) & $43 \pm 13$ & $42 \pm 12$ & $40 \pm 12$ & .71 \\
\hline$E / E^{\prime}(n=5, n=13, n=7)$ & $21.4 \pm 19.4$ & $21.2 \pm 11.0$ & $15.0 \pm 8.7$ & .33 \\
\hline ACE-inhibitor or AllA (\%) & 100 & 74 & 86 & .16 \\
\hline$\%$ optimal daily dosage & $73 \pm 26$ & $96 \pm 32$ & $88 \pm 61$ & .15 \\
\hline Selective $\beta$-blocker (\%) & 73 & 77 & 86 & .75 \\
\hline$\%$ optimal daily dosage & $41 \pm 17$ & $52 \pm 27$ & $52 \pm 25$ & .56 \\
\hline Non-selective $\beta$-blocker (\%) & 18 & 13 & 7 & .75 \\
\hline$\%$ optimal daily dosage & $150 \pm 71$ & $137 \pm 75$ & $50 \pm 0$ & .40 \\
\hline Diuretic (\%) & 64 & 84 & 71 & .32 \\
\hline$\%$ usual daily dosage & $113 \pm 67$ & $103 \pm 73$ & $129 \pm 106$ & .75 \\
\hline $\mathrm{BNP}(\mathrm{pg} / \mathrm{mL})$ & $167 \pm 120$ & $177 \pm 207$ & $293 \pm 383$ & .39 \\
\hline $\mathrm{HbA1c}(\%)$ & $5.3 \pm 0.2$ & $5.7 \pm 0.3$ & $5.9 \pm 0.3$ & $.01^{*}$ \\
\hline Total cholesterol (mg/dL) & $176 \pm 39$ & $173 \pm 45$ & $169 \pm 53$ & .81 \\
\hline HDL cholesterol (mg/dL) & $43 \pm 11$ & $50 \pm 15$ & $49 \pm 15$ & .39 \\
\hline LDL cholesterol (mg/dL) & $107 \pm 29$ & $93 \pm 32$ & $88 \pm 42$ & .25 \\
\hline Triglycerides (mg/dL) & $131 \pm 35$ & $159 \pm 101$ & $160 \pm 88$ & .94 \\
\hline Body weight (kg) & $76.5 \pm 15.8$ & $76.5 \pm 16.5$ & $82.9 \pm 30.0$ & .10 \\
\hline Fat mass (\%) & $31.1 \pm 6.9$ & $35.2 \pm 9.1$ & $34.8 \pm 9.2$ & .52 \\
\hline Lean mass (kg) & $52.2 \pm 9.3$ & $49.3 \pm 9.7$ & $52.2 \pm 12.4$ & .62 \\
\hline Fat trunk/fat limb ratio & $1.28 \pm 0.39$ & $1.39 \pm 0.26$ & $1.63 \pm 0.35$ & $.03^{* *}$ \\
\hline \multicolumn{5}{|l|}{ Extension strength $(\mathrm{Nm} / \mathrm{kg})$} \\
\hline $45^{\circ}$ & $16.8 \pm 6.1$ & $13.9 \pm 2.9$ & $13.7 \pm 5.1$ & .32 \\
\hline $90^{\circ}$ & $16.6 \pm 3.0$ & $15.4 \pm 4.1$ & $15.3 \pm 6.4$ & .58 \\
\hline \multicolumn{5}{|l|}{ Flexion strength $(\mathrm{Nm} / \mathrm{kg})$} \\
\hline $45^{\circ}$ & $9.0 \pm 2.8$ & $8.2 \pm 2.2$ & $7.8 \pm 3.4$ & .89 \\
\hline $90^{\circ}$ & $7.5 \pm 2.2$ & $6.7 \pm 1.9$ & $6.2 \pm 2.4$ & .60 \\
\hline Self-reported physical activity (METminutes/day) & $1921(533-4313)$ & $1872(1789-4047)$ & $1219(664-5686)$ & .73 \\
\hline
\end{tabular}

$B M I$, body mass index; $B N P$, B-type natriuretic peptide; $I H D$, ischaemic heart disease; $L V E F$, left ventricular ejection fraction; $N G T$, normal glucose tolerance; NYHA, New York heart association functional class. Extension and flexion strength are expressed as peak torque relative to lean tissue of the right leg. Continuous variables are presented as mean \pm SD, physical activity is presented as mean and $95 \%$ confidence interval. Categorical variables are presented as number and percentage.

*NGT versus prediabetes and diabetes, **post hoc differences not significant after Bonferroni correction.

whole body glucose uptake in CHF, results are not conclusive. More studies using standardized glucose tolerance assessment and supervised exercise interventions are needed [26].

\section{Glucose tolerance in relation to severity of heart failure}

Previous studies describing EF as a determinant for glucose tolerance were performed in $\mathrm{CHF}$ patients with reduced EF [4,7,27]. In addition, an association between diastolic function and impaired glucose tolerance in
CHF patients with preserved EF has been reported [28-30]. Because we included patients with reduced as well as preserved EF, we expected to find a relation between glucose tolerance and EF with worse glucose tolerance in patients with preserved EF. However, mixed model analysis showed no influence of EF on overall glucose values or shape of the glucose curve. Likewise, BNP was not associated with glucose curve. Also, a stepwise increase along the diabetic continuum as shown by Stahrenbergh et al and Dinh et al was not present in this 
study population $[28,30]$. On the other side, E/E', a marker of left ventricular end-diastolic pressure, appeared to be a contributing factor for glucose response during OGTT.

\section{Glucose tolerance in relation to typical CHF medical therapies}

Almost all patients in the study group were optimally treated, and therefore pharmacological treatment between groups was similar. Our hypothesis that glucose tolerance is related to the intake and dosage of typical CHF medical therapies was therefore not confirmed.

\section{Glucose tolerance in relation to body composition and skeletal muscle strength}

The classic link of glucose intolerance with increasing obesity was confirmed. Interestingly, a greater importance of fat mass and fat distribution (trunk fat/limb fat) was shown compared to lean mass. The ideal body weight for $\mathrm{CHF}$ patients has been the subject of debate. On the one hand, a low body mass index is a risk factor for mortality in CHF while the presence of obesity (body mass index $30-35 \mathrm{~kg} / \mathrm{m}^{2}$ ) is associated with lower mortality [15]. On the other hand, more detailed body composition parameters may give another view on the beneficial effects of obesity in CHF. Oreopoulos et al suggested that higher lean mass is protective in CHF, while fat mass is associated with detrimental effects as higher fasting glucose [16]. As higher fat mass and fat distribution around the trunk were predictors for glucose response in the present study, our data agree with this logic. However, although lean mass was quantitatively not different between groups, it is probable that muscle quality and function are decisive factors for glucose tolerance. In this respect, Doehner et al have showed the decreased glucose transporter protein type 4 in skeletal muscle of CHF patients, independent of body composition [5].

Muscle function in terms of extension strength of the upper leg was related to overall glucose values, but was not a predictor for glucose tolerance when combined with other variables. In addition, extension strength was negatively correlated with fasting insulin values. This confirms our hypothesis that higher skeletal muscle strength is associated with better glucose tolerance. Although we believe that higher muscle strength is a reflection of increased levels of physical activity, this was not confirmed by the results of physical activity assessment with the International Physical Activity Questionnaire.

This study has some limitations. Echocardiographic data were retrieved from hospital records and were not prospectively assessed. Physical activity was assessed by questionnaire, although it does not reflect true physical activity as compared to pedometers and accelerometers.
Furthermore, cardiopulmonary exercise tolerance and isokinetic strength endurance assessment could have added valuable information to the predictive model. Finally, the study did not include healthy controls.

\section{Conclusions}

The proportion of glucose intolerant $\mathrm{CHF}$ patients is alarmingly high, and is underestimated when screening only fasting glucose and HbA1c. Our data did not show an association between glucose tolerance and EF, New York Heart Association class, nor medication use. However, glucose tolerance was associated with left ventricular end-diastolic pressure and body fat distribution.

\section{Abbreviations}

CHF: Chronic heart failure; EF: Ejection fraction; OGTT: Oral glucose tolerance test.

\section{Competing interests}

The authors declare that they have no competing interests.

\section{Authors' contributions}

AS conceived of the study, performed the data collection, statistical analysis, interpretation of data and drafted the manuscript. DH participated in interpretation of data and drafting the manuscript. W and RW helped setting up the study, performed data collection and statistical analyses. AC gave statistical counseling and performed statistical analyses (mixed models). $\mathrm{BO}$ and PD were involved in the conceiving of the study and in the interpretation of data as well as drafting the manuscript. All authors read and approved the final manuscript.

\section{Acknowledgements}

The authors would like to thank Marita Houbrechts, Lieven Herbots and Joke Vanhoof, without whose help this study would not have been possible. This study is part of the Limburg Clinical Research Program (LCRP) UHasselt-ZOL-Jessa, and was supported by the foundation Limburg Sterk Merk. This work received support from Flanders' Training Network for Methodology and Statistics (FLAMES). Blood samples are stored at the University Biobank Limburg (UBiLim).

\section{Author details}

${ }^{1}$ REVAL Rehabilitation Research Centre, Hasselt University, Martelarenlaan 42, BE-3500 Hasselt, Belgium. ${ }^{2}$ Heart Centre Hasselt, Jessa Hospital, Stadsomvaart 11, BE-3500 Hasselt, Belgium. ${ }^{3}$ I-BioStat, Hasselt University, Martelarenlaan 42, BE-3500 Hasselt, Belgium.

Received: 13 January 2014 Accepted: 19 March 2014

Published: 27 March 2014

\section{References}

1. Katz AM, Konstam MA: Heart failure: pathophysiology, molecular biology, and clinical management. Philadelphia: Wolters Kluwer Health/Lippincott Williams \& Wilkins; 2009.

2. Mamas MA, Deaton C, Rutter MK, Yuille M, Williams SG, Ray SG, New J, Gibson JM, Neyses L: Impaired glucose tolerance and insulin resistance in heart failure: underrecognized and undertreated? J Card Fail 2010, 16:761-768

3. Egstrup M, Schou M, Gustafsson I, Kistorp CN, Hildebrandt PR, Tuxen CD: Oral glucose tolerance testing in an outpatient heart failure clinic reveals a high proportion of undiagnosed diabetic patients with an adverse prognosis. Eur J Heart Fail 2011, 13:319-326.

4. AlZadjali MA, Godfrey V, Khan F, Choy A, Doney AS, Wong AK, Petrie JR, Struthers AD, Lang CC: Insulin resistance is highly prevalent and is associated with reduced exercise tolerance in nondiabetic patients with heart failure. J Am Coll Cardiol 2009, 53:747-753.

5. Doehner W, Gathercole D, Cicoira M, Krack A, Coats AJ, Camici PG, Anker SD: Reduced glucose transporter GLUT4 in skeletal muscle predicts 
insulin resistance in non-diabetic chronic heart failure patients independently of body composition. Int J Cardiol 2010, 138:19-24.

6. Parsonage W, Hetmanski D, Cowley A: Differentiation of the metabolic and vascular effects of insulin in insulin resistance in patients with chronic heart failure. Am J Cardiol 2002, 89:696-703.

7. Sabelis LW, Senden PJ, Zonderland ML, van de Wiel A, Wielders JP, Huisveld IA, van Haeften TW, Mosterd WL: Determinants of insulin sensitivity in chronic heart failure. Eur J Heart Fail 2003, 5:759-765.

8. Snoer M, Monk-Hansen T, Olsen RH, Pedersen LR, Simonsen L, Rasmusen H, Dela F, Prescott E: Insulin resistance and exercise tolerance in heart failure patients: linkage to coronary flow reserve and peripheral vascular function. Cardiovasc Diabetol 2012, 11:97.

9. Suskin N, McKelvie RS, Burns RJ, Latini R, Pericak D, Probstfield J, Rouleau JL, Sigouin C, Solymoss CB, Tsuyuki R, White M, Yusuf S: Glucose and insulin abnormalities relate to functional capacity in patients with congestive heart failure. Eur Heart J 2000, 21:1368-1375.

10. Carella AM, Antonucci G, Conte M, Di PM, Giancola A, Antonucci E: Antihypertensive treatment with beta-blockers in the metabolic syndrome: a review. Curr Diabetes Rev 2010, 6:215-221.

11. Doehner W, Anker SD: Beta blockers and glucose metabolism in chronic heart failure: friend or foe? Clin Res Cardiol 2008, 97:21-23.

12. Kostis JB, Sanders M: The association of heart failure with insulin resistance and the development of type 2 diabetes. Am J Hypertens 2005, 18:731-737

13. MacDonald MR, Petrie MC, Hawkins NM, Petrie JR, Fisher M, McKelvie R, Aguilar D, Krum H, McMurray JJ: Diabetes, left ventricular systolic dysfunction, and chronic heart failure. Eur Heart J 2008, 29:1224-1240.

14. Carter BL, Einhorn PT, Brands M, He J, Cutler JA, Whelton PK, Bakris GL, Brancati FL, Cushman WC, Oparil S, Wright JT Jr: Thiazide-induced dysglycemia: call for research from a working group from the national heart, lung, and blood institute. Hypertension 2008, 52:30-36.

15. Anker SD, von Haehling S: The obesity paradox in heart failure: accepting reality and making rational decisions. Clin Pharmacol Ther 2011, 90:188-190.

16. Oreopoulos A, Ezekowitz JA, McAlister FA, Kalantar-Zadeh K, Fonarow GC, Norris CM, Johnson JA, Padwal RS: Association between direct measures of body composition and prognostic factors in chronic heart failure. Mayo Clin Proc 2010, 85:609-617.

17. Hulsmann M, Quittan M, Berger R, Crevenna R, Springer C, Nuhr M, Mortl D, Moser $\mathrm{P}$, Pacher R: Muscle strength as a predictor of long-term survival in severe congestive heart failure. Eur J Heart Fail 2004, 6:101-107.

18. Ryden L, Standl E, Bartnik M, Van den Berghe G, Betteridge J, de Boer MJ, Cosentino F, Jonsson B, Laakso M, Malmberg K, Priori S, Ostergren J, Tuomilehto J, Thrainsdottir I, Vanhorebeek I, Stramba-Badiale M, Lindgren P, Qiao Q, Priori SG, Blanc JJ, Budaj A, Camm J, Dean V, Deckers J, Dickstein K, Lekakis J, McGregor K, Metra M, Morais J, Osterspey A, et al: Guidelines on diabetes, pre-diabetes, and cardiovascular diseases: executive summary. The Task Force on Diabetes and Cardiovascular Diseases of the European Society of Cardiology (ESC) and of the European Association for the Study of Diabetes (EASD). Eur Heart J 2007, 28:88-136.

19. American Diabetes Association: Standards of medical care in diabetes-2011. Diabetes Care 2011, 34(Suppl 1):S11-S61.

20. Tietz NW, Amerson AB: Clinical guide to laboratory tests. Collingwood: Saunders; 2013.

21. The EuroQoL group: EuroQol-a new facility for the measurement of health-related quality of life. Health Policy 1990, 16:199-208.

22. Brooks R, Rabin R, Charro F: The Measurement and Valuation of Health Status Using EQ-5D: A European Perspective. Dordrecht: Kluwer Academic Publishers; 2003

23. Molenberghs G, Kenward M: Multiple Imputation. In Missing data in clinical studies. New York: John Wiley \& Sons; 2007:105-117.

24. Doehner W, Rauchhaus M, Ponikowski P, Godsland IF, Von HS, Okonko DO, Leyva F, Proudler AJ, Coats AJ, Anker SD: Impaired insulin sensitivity as an independent risk factor for mortality in patients with stable chronic heart failure. J Am Coll Cardiol 2005, 46:1019-1026.

25. McMurray JJ, Adamopoulos S, Anker SD, Auricchio A, Bohm M, Dickstein K, Falk V, Filippatos G, Fonseca C, Gomez-Sanchez MA, Jaarsma T, Kober L, Lip GY, Maggioni AP, Parkhomenko A, Pieske BM, Popescu BA, Ronnevik PK, Rutten FH, Schwitter J, Seferovic P, Stepinska J, Trindade PT, Voors AA Zannad F, Zeiher A: ESC Guidelines for the diagnosis and treatment of acute and chronic heart failure 2012: The Task Force for the Diagnosis and Treatment of Acute and Chronic Heart Failure 2012 of the European Society of Cardiology. Developed in collaboration with the Heart Failure Association (HFA) of the ESC. Eur Heart J 2012, 33:1787-1847.

26. Stevens A, Hansen D, Op 't Eijnde B, Dendale P: Exercise intervention to improve glucose tolerance in patients with heart failure: a review. In Treatment Strategies-Cardiology. 3rd edition. Edited by Laura H. London: Cambridge Research Centre; 2012:59-64

27. Swan JW, Anker SD, Walton C, Godsland IF, Clark AL, Leyva F, Stevenson JC, Coats AJ: Insulin resistance in chronic heart failure: relation to severity and etiology of heart failure. J Am Coll Cardiol 1997, 30:527-532.

28. Stahrenberg R, Edelmann F, Mende M, Kockskamper A, Dungen HD, Scherer M, Kochen MM, Binder L, Herrmann-Lingen C, Schonbrunn L, Gelbrich G, Hasenfuss G, Pieske B, Wachter R: Association of glucose metabolism with diastolic function along the diabetic continuum. Diabetologia 2010, 53:1331-1340

29. Bajraktari G, Koltai MS, Ademaj F, Rexhepaj N, Qirko S, Ndrepepa G, Elezi S: Relationship between insulin resistance and left ventricular diastolic dysfunction in patients with impaired glucose tolerance and type 2 diabetes. Int J Cardiol 2006, 110:206-211.

30. Dinh W, Lankisch M, Nickl W, Scheyer D, Scheffold T, Kramer F, Krahn T, Klein RM, Barroso MC, Futh R: Insulin resistance and glycemic abnormalities are associated with deterioration of left ventricular diastolic function: a cross-sectional study. Cardiovasc Diabeto/ 2010, 9:63-75.

doi:10.1186/1758-5996-6-44

Cite this article as: Stevens et al:: Mandatory oral glucose tolerance tests identify more diabetics in stable patients with chronic heart failure: a prospective observational study. Diabetology \& Metabolic Syndrome 2014 6:44.

\section{Submit your next manuscript to BioMed Central and take full advantage of:}

- Convenient online submission

- Thorough peer review

- No space constraints or color figure charges

- Immediate publication on acceptance

- Inclusion in PubMed, CAS, Scopus and Google Scholar

- Research which is freely available for redistribution 